\title{
Detection of Cells Displaying High Expression of CLIC4 in Tumor Tissue of Patients With Colorectal Cancer
}

\author{
REO YOKOYAMA ${ }^{1}$, ATSUHITO KUBOTA ${ }^{1}$, HIROYUKI KOJIMA ${ }^{1,2}$, \\ TAKUJI TANAKA ${ }^{3}$, MICHIHIRO MUTOH ${ }^{4}$ and MASARU TERASAKI ${ }^{1,2}$ \\ ${ }^{1}$ School of Pharmaceutical Sciences and ${ }^{2}$ Advanced Research Promotion Center, \\ Health Sciences University of Hokkaido, Hokkaido, Japan; \\ ${ }^{3}$ Department of Diagnostic Pathology and Research Center of Diagnostic Pathology, \\ Gifu Municipal Hospital, Gifu, Japan; \\ ${ }^{4}$ Department of Molecular-Targeting Prevention, Graduate School of Medical Science, \\ Kyoto Prefectural University of Medicine, Kyoto, Japan
}

\begin{abstract}
Background/Aim: Chloride intracellular channel 4 (CLIC4) is associated with the progression of colorectal cancer (CRC). However, quantitative differences in CLIC4 expression in epithelial and stromal cells of normal mucosal tissue (NT), cancer adjacent to normal colorectal mucosal tissue (NAT), and CRC tissue remain unclear. Materials and Methods: We investigated the number of CLIC4 highexpressing (CLIC4 $\left.4^{\text {high }}\right)$ cells in colorectal tissue of CRC patients and healthy individuals. Results: The number of CLIC4 $4^{\text {high }}$ cells in malignant epithelial cells at early cancerous lesions was significantly higher than that in NAT, but was significantly lower or tended to become low corresponding to the progression of colorectal carcinogenesis. Meanwhile, the number of CLIC $4^{\text {high }}$ cells in the stromal tissue remained low in NAT compared to late lesions. Conclusion: The number of CLIC $4^{\text {high }}$ cells is a useful predictor in determining the pathological condition in both malignant epithelial and stromal tissues of CRC patients.
\end{abstract}

Chloride intracellular channel 4 (CLIC4), a small globular protein $(28 \mathrm{kDa})$, that belongs to the CLIC family (CLIC1, CLIC2, CLIC3, CLIC4, CLIC5A, CLIC5B, and CLIC6), and is known to function as a putative chloride channel that

This article is freely accessible online.

Correspondence to: Masaru Terasaki, School of Pharmaceutical Sciences and Advanced Research Promotion Center, Health Sciences University of Hokkaido, 1757 Kanazawa, Ishikari-Tobetsu, Hokkaido 061-0293, Japan. Tel: +81 133231211 ext. 3156, Fax: +81 133231669, e-mail: terasaki@hoku-iryo-u.ac.jp

Key Words: Chloride intracellular channel 4, colon cancer, malignant cell, stromal cell, pathological stage. regulates cellular redox (1-3). CLIC4 is ubiquitously distributed in the cytoplasm, subcellular mitochondria, endoplasmic reticulum, and nuclear membrane $(3,4)$, and plays an important role in the regulation of development, such as endothelial morphogenesis and angiogenesis $(5,6)$. Recently, CLIC4 has gained attention as a significant cancerregulating molecule. CLIC4 is broadly expressed in cancer tissues of patients with various types of cancers (7). Previously, several studies had demonstrated that CLIC4 expression is regulated by factors such as tumor suppressor p53, c-MYC, tumor necrosis factor (TNF)- $\alpha$, and transforming growth factor (TGF)- $\beta$, and is expressed during cell differentiation and DNA damage (4, 8-10). CLIC4 positively or negatively affects the signals of Kirsten-ras (KRAS) and p38 mitogen-activated protein kinase (MAPK), induction of inducible nitric oxide synthase, apoptosis, cell growth, cell migration, invasion, epithelial mesenchymal transition (EMT), immune function, loss of mitochondrial membrane potential, endoplasmic reticulum stress, microRNAs, hypermethylation and tumorigenesis, as well as through differentiation of myofibroblasts and formation of the tumor microenvironment (TME) $(7,11-18)$. However, the function of CLIC4 depends on the type of cancer, and its variation in each cell remains elusive.

Worldwide, colorectal cancer (CRC) is a disease that exhibits a high incidence as well as mortality rate (19). Many aberrations of genes, proteins, and other molecules, such as gene mutations (e.g., KRAS and $A P C$ ), gene fusions, hypermethylation, transcriptomes, microRNAs, core signal transduction, immune functions and TME formation, have contributed to initiation and promotion of CRC (20-28). CLIC4 is assumed to play an important role in these complex aberrations that contribute toward the onset of CRC. Two reports have demonstrated that the expression of human CLIC4 is negatively associated with pathological grades of 
CRC and with poor prognosis (7, 29). In addition, a clear association has been shown between CLIC4 expression and metastatic potential of CRC stem-like cells (29). Furthermore, CLIC4 expression in malignant stromal cells is elevated corresponding to an increase in the histopathological grade of CRC (7). The high CLIC4expressing stromal cells are often related to myofibroblasts, which largely correspond to cancer-associated fibroblasts (CAFs) characterized by high levels of $\alpha$-smooth muscle actin ( $\alpha$-SMA). CAFs are essential cells that assemble the TME and play a role in cancer stemness, invasion, metastasis, EMT, tumorigenesis, angiogenesis, hyperplasia of extracellular matrix, and immune response (7, 30-35). Thus, CLIC4 could be used as a biological marker representing the progression of histopathological grade of $\mathrm{CRC}$ and accumulation of CAFs in CRC tissue. However, differences in CLIC4 expression in colorectal epithelial cells and stromal cells among normal tissue (NT), cancer adjacent to normal colorectal tissue (NAT), and CRC tissue corresponding to the classification of cancer stages and tumor-node-metastasis (TNM) remains unclear.

In the present study, we elucidated quantitative differences in CLIC4 expression in the colorectal epithelial and stromal cells among NT, NAT, and CRC tissue at various pathological stages of cancer.

\section{Materials and Methods}

Chemicals. Anti-CLIC4-Alexa Fluor 488 mouse monoclonal antibody was obtained from Santa Cruz Biotechnology (Santa Cruz, CA, USA). Bovine serum albumin (BSA) was obtained from Nacalai Tesque (Kyoto, Japan). ProLong Gold Antifade reagent with 4',6-diamidino-2-phenylindole (DAPI) was purchased from Invitrogen (Carlsbad, CA, USA). All other solvents and chemicals were of analytical grade.

Human tissues. Human CRC tissue arrays (catalog nos. CO242b, $\mathrm{CO} 243 \mathrm{a}, \mathrm{CO} 243 \mathrm{~b}$, and $\mathrm{CO} 483 \mathrm{~b}$ ) were purchased from US Biomax (Rockville, MD, USA). The arrays included 79 CRC cases, which had been characterized by age, sex, anatomic site, pathology diagnosis, TNM grading, grade, and stage. Eighteen NTs and 15 NATs were used as control samples. The company conserves the informed written consent obtained from CRC patients (or their relatives) whose tissues were used to prepare the tissue arrays. Detailed information on all cancers, NTs, and NATs can be viewed at http://www.biomax.us/tissue-arrays/Colon.

Fluorescence immunohistochemistry. Paraffin-embedded tissue arrays were de-waxed by immersion in xylene, and then washed by immersion in anhydrous ethanol, 95\% ethanol in aqueous solution, and distilled water. Antigens were retrieved from the tissue sections by treating them with $1 \mathrm{mM}$ EDTA buffer $\left(\mathrm{pH} \mathrm{9.0)}\right.$ ) at $95^{\circ} \mathrm{C}$ for 20 min and washing with distilled water and Tris-buffer saline containing $0.1 \%$ polyoxyethylene (20) sorbitan monolaurate (TBS$\mathrm{T})$. The sections were incubated with $5 \%$ bovine serum albumin $(\mathrm{BSA}) / \mathrm{TBS}-\mathrm{T}(\mathrm{w} / \mathrm{v})$ at room temperature for $1 \mathrm{~h}$ and later incubated
Table I. Characteristics of patients with colon cancer.

\begin{tabular}{lccc}
\hline Classification & $\begin{array}{c}\text { Cancer } \\
(\mathrm{N}=79)\end{array}$ & $\begin{array}{c}\mathrm{NAT} \\
(\mathrm{N}=15)\end{array}$ & $\begin{array}{c}\mathrm{NT} \\
(\mathrm{N}=18)\end{array}$ \\
\hline Median age (IQR) -yr & 55.9 & 61.4 & 30.2 \\
& $(47.0-67.0)$ & $(50.5-70.5)$ & $(29.5-30.5)$ \\
Gender & $23(29.1)$ & $4(27.0)$ & $0(0 \%)$ \\
Female (\%) & $56(70.9)$ & $11(73.0)$ & $18(100 \%)$ \\
Male (\%) & & & \\
Histopathology (N=78)* & $22(28.2)$ & & \\
Grade 1 - no. (\%) & $35(44.9)$ & & \\
Grade 2 - no. (\%) & $2(2.6)$ & & \\
Grade 2--3 - no. $\%)$ & $19(24.3)$ & & \\
Grade3 - no. (\%) & $7(8.9)$ & & \\
Stage (N=79) & $19(24.0)$ & & \\
Stage I - no. (\%) & $13(16.5)$ & & \\
Stage IIa - no. (\%) & $34(43.0)$ & & \\
Stage IIb - no. (\%) & $6(7.6)$ & & \\
Stage IIIb - no. (\%) & & & \\
Stage IIIc - no. (\%) & $7(8.9)$ & & \\
Primary tumor stage (N=79) & & \\
T2 - no. (\%) & $37(46.8)$ & \\
T3 - no. (\%) & $35(44.3)$ & \\
T4 - no. (\%) & & \\
Lymph node (N=81) & $41(50.6)$ & \\
N0 - no. (\%) & $30(37.0)$ & \\
N1 - no. (\%) & $10(12.4)$ & \\
N2 - no. (\%) & $79(100)$ & \\
Metastasis (N=79) & & \\
M0 - no. (\%) & & \\
\hline
\end{tabular}

NAT, Cancer adjacent normal colorectal tissue; NT, normal colorectal tissue; IQR, interquatile range. *One of 79 patients with CRC was not classified the histopathological grade. Therefore, it became $\mathrm{N}=78$.

at $4^{\circ} \mathrm{C}$ for $20 \mathrm{~min}$. Subsequently, the sections were incubated with an anti-CLIC4-Alexa Fluor 488 mouse monoclonal antibody diluted $1: 50$ in $5 \% \mathrm{BSA} / \mathrm{TBS}-\mathrm{T}$ overnight at $4^{\circ} \mathrm{C}$. Next, the sections were washed with TBS-T and PBS, and finally covered with ProLong Gold Antifade reagent containing DAPI. Immunofluorescence images were acquired using a Nikon TE2000 confocal microscope equipped with EZ-C1 software (Nikon, Tokyo, Japan). The number of high-intensity CLIC4 (CLIC4high) cells in the cancer or stromal tissue per tissue area $\left(\mathrm{mm}^{2}\right)$ was measured by panel photography using the confocal microscope.

Statistical analysis. All data are expressed as the mean \pm standard error (SE). Significant differences between two groups were assessed using Student's $t$-test. Multiple comparisons were conducted using one-way analysis of variance (ANOVA) followed by post-hoc Tukey-Kramer test. Significant differences are expressed as ${ }^{*} p<0.05 ; * * p<0.01$.

\section{Results}

Characteristics of patients with colorectal cancer. Table I shows the basic and pathological characteristics of patients with CRC and healthy individuals. Median age of CRC patients was 55.9 years (range $=47.0-67.0$ years). Median age 
of sample donors of NAT and NT was 61.4 years (range $=50.5-70.5$ years) and 30.2 years (a small range was observed; 29.5-30.5 years), respectively. The percentages of female participants were $29.1 \%, 27.0 \%$, and $0 \%$ in CRC, NAT, and NT, respectively. Pathological stages, such as grade $2(44.9 \%)$, stage IIIb $(43.0 \%)$, T3 $(46.8 \%)$, N0 (50.6\%), and M0 (100\%) were found in the majority of CRC patients.

Protein expression levels of CLIC4 in malignant epithelial and stromal cells of patients with colorectal cancer. To evaluate differences in protein expression levels of CLIC4 in NT, NAT, and colorectal adenocarcinoma in patients and/or healthy individuals, the number of CLIC4 ${ }^{\text {high }}$ cells in normal crypt area, malignant epithelial area, and/or stromal area were determined by fluorescent immunohistochemical analysis. CLIC $4^{\text {high }}$ cells were detected in the all the epithelial and stromal tissues of NT, NAT, and colorectal adenocarcinoma (Figure 1). The number of CLIC $4{ }^{\text {high }}$ cells in normal crypt area of NT and NAT or in malignant epithelial tissue area were significantly lower compared to those in the corresponding peripheral stroma area: normal crypt area of NT, $46.7 \pm 14.2$; normal crypt area of NAT, $17.5 \pm 3.9$; malignant epithelial area of adenocarcinoma, $38.6 \pm 4.0$; stromal area of NT, 357.3 \pm 39.0 ; stromal area of NAT, 441.3 \pm 41.4 ; stromal area of adenocarcinoma, $308.0 \pm 18.0$. No significant difference in the number of CLIC $4^{\text {high }}$ cells was observed among normal crypt areas of NT and NAT and malignant epithelial area, or among areas of the corresponding peripheral stroma. However, differences were observed between the stroma areas of NAT and adenocarcinoma. The numbers of CLIC $4^{\text {high }}$ cells in the stromal areas of NT, NAT, and adenocarcinoma were 7.6-, 25.3-, and 8.0-fold higher than that in the corresponding epithelial areas, respectively (Figure 2).

Next, protein expression of CLIC4 at each pathological classification stage was quantitatively evaluated between malignant epithelial areas (Figure 3) and stromal areas (Figure 4). The number of CLIC $4^{\text {high }}$ cells in the malignant epithelial area at grade 1, stage I and T2 were significantly increased by 2.9-, 4.2-, and 4.2-fold, respectively, than that in normal crypt area of NAT (Figure 3A, B, and C). However, no significant difference was observed in the number of CLIC4 ${ }^{\text {high }}$ cells in the malignant epithelial area among grades 1, 2, 2-3 and 4 (Figure 3A). The number of CLIC $4^{\text {high }}$ cells in the malignant epithelial area at stages IIb and IIIb was significantly lower than that at stage I (Figure 3B). Likewise, the number of CLIC $4^{\text {high }}$ cells in the malignant epithelial area at T4 was significantly lower than that at T2 (Figure 3C). No significant difference was observed in the number of CLIC $4^{\text {high }}$ cells in the malignant epithelial area among N0, N1 and N2 TNM classifications (Figure 3D).
The number of CLIC $4{ }^{\text {high }}$ cells in the stromal area at grades 1 and 3, stage IIIb, T4, and N1 was significantly decreased compared with that in the stromal area of NAT (Figure 4A-D).

\section{Discussion}

The present study demonstrated that the number of CLIC4 ${ }^{\text {high }}$ cells in malignant epithelial tissue of CRC patients at early cancerous lesions (grade 1, stage I, and T2) was significantly higher than that in NAT, and then significantly decreased or tended to be low along with the progression of colorectal carcinogenesis. In addition, the number of CLIC4 ${ }^{\text {high }}$ cells in the stromal tissue at grades 1 and 3, stage IIIb, T4, and N1 was lower than that in the stromal tissue of the corresponding NATs. This is the first report that reveals quantitative differences in CLIC4 expression in colorectal cancer epithelial tissue and stromal tissue at three pathological classifications (grade, stage, and TNM) and NAT in CRC patients and in NT of healthy individuals.

First, we quantitatively evaluated CLIC $4^{\text {high }}$ cells in epithelial and stromal tissues of NAT and adenocarcinoma in CRC patients and NT of healthy individuals. A negligible difference in the number of CLIC4 $4^{\text {high }}$ cells was observed among NT, NAT, and adenocarcinoma in both the epithelial and stromal tissues. However, there was a difference between the stromal tissue of NAT and adenocarcinoma; the number of CLIC4 ${ }^{\text {high }}$ cells in each stromal tissue was 7.6to 25.3-fold higher than in normal crypts of NT, NAT, and malignant epithelial cells (Figure 2). Interestingly, a large number of CLIC4 $4^{\text {high }}$ cells were detected in NT and NAT. Generally, it has been reported that CLIC4 protein expression is very low in stromal cells, except for vascular endothelial cells $(6,7)$. However, we speculate that previous researchers might not have measured CLIC4-positive cells per tissue area in colorectal NT and NAT and therefore failed to clarify the role of CLIC4-expressing cells in colorectal stromal tissue.

Overexpression of CLIC4 in fibroblasts augments the expression of $\alpha \mathrm{SMA}$, an activated fibroblast marker in CAFs, and induces myofibroblast transformation in the stroma of tumors $(7,13)$. A majority of myofibroblasts covering tumor tissue is CAFs. The CAFs present in the stroma of tumors play an important role in the regulation of epithelial mesenchymal transition, angiogenesis, extracellular matrix (ECM) remodeling, tumorigenesis, drug accessibility, drug sensitivity and immune function, and production of growth and inflammation factors $(26,27,35)$. Inflammatory factors such as TGF- $\beta$ and TNF can induce the transformation of normal fibroblasts into CAFs $(27,35)$. Notably, CLIC4 is up-regulated by TGF- $\beta$ and TNF- $\alpha(4,9)$. Therefore, we speculate that the function of stromal CLIC4 ${ }^{\text {high }}$ cells in normal-looking tissue may have potential close to CAFs. 

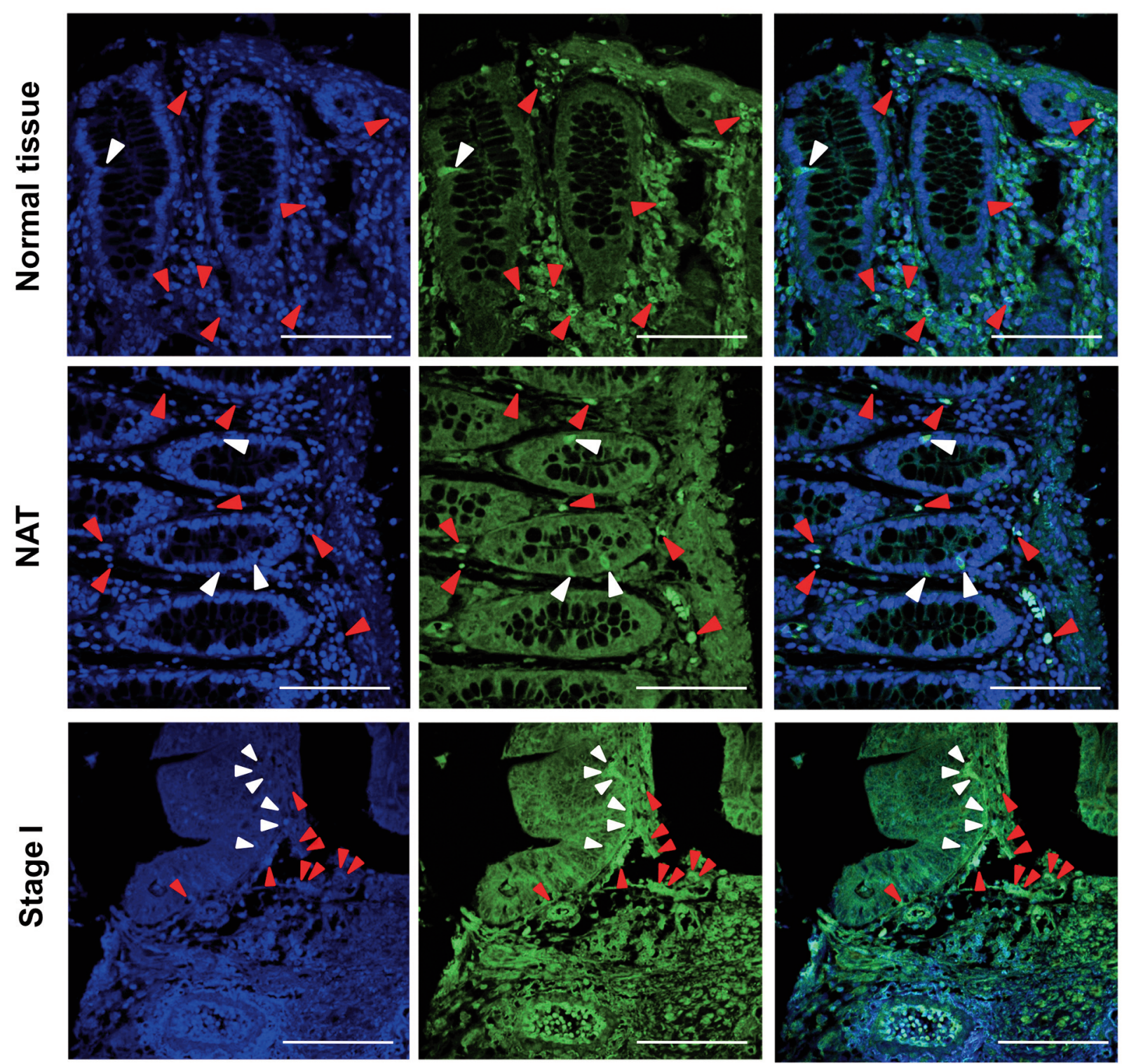

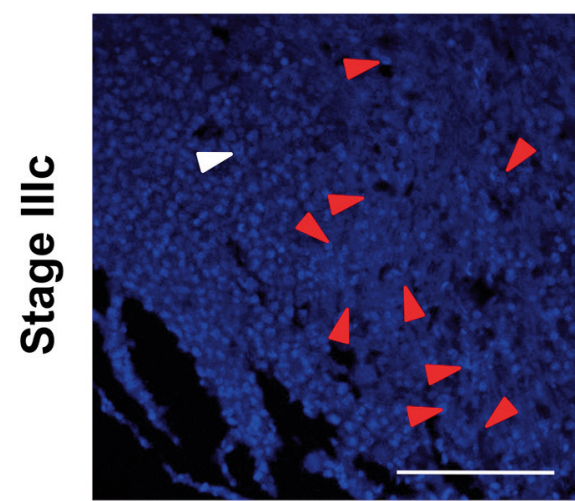

Nuclei

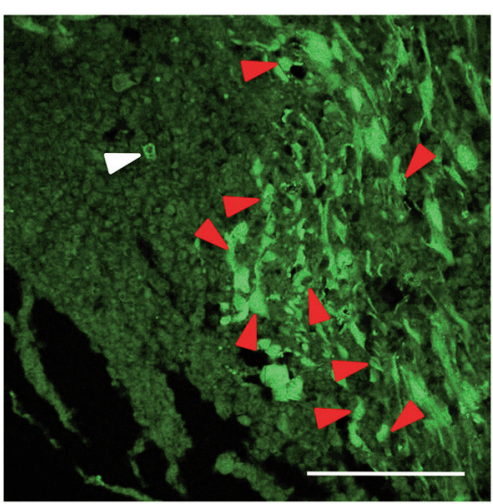

CLIC4 ${ }^{\text {high }}$

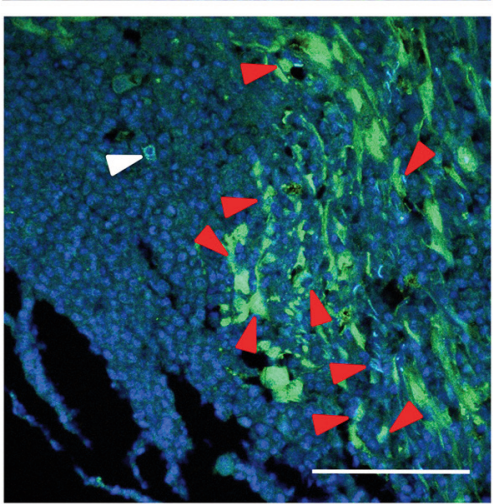

Merge

Figure 1. Detection of CLIC4high cells in the human colorectal tissue. The nuclei (blue fluorescence) and CLIC4 (green fluorescence) were observed by confocal microscopy. White arrow heads in normal crypt cells or malignant epithelial cells, and red arrow heads in stromal cells show the cells with high expression of CLIC4 (CLIC4high). White bars are $100 \mu \mathrm{m}$. NAT, Cancer adjacent normal colorectal tissue. 


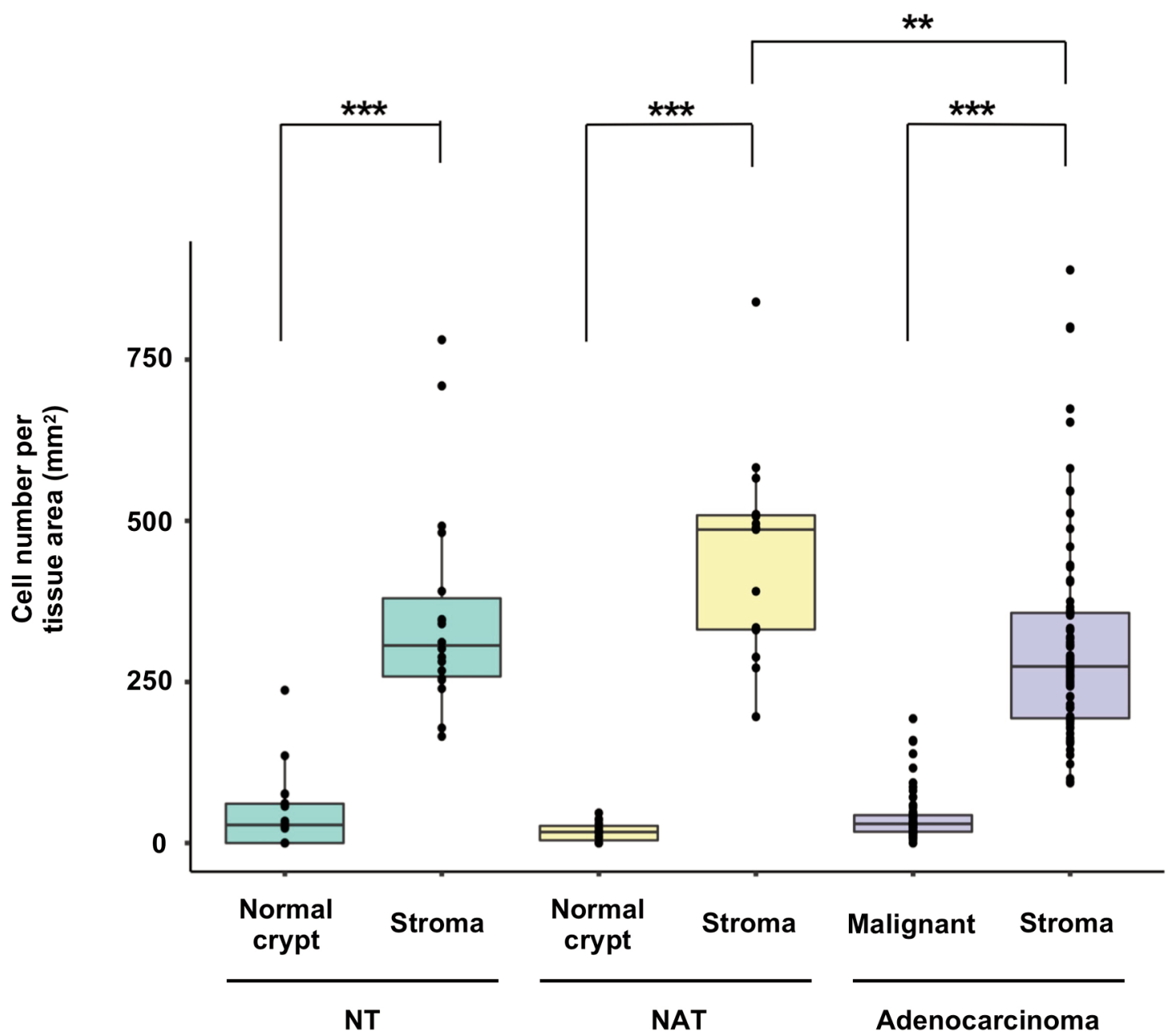

Figure 2. The different number of CLIC4high cells in normal and malignant tissue. The number of CLIC4high cells per tissue area $\left(\mathrm{mm}^{2}\right)$ were measured in normal colorectal tissue (NT), cancer adjacent normal colorectal tissue (NAT) and adenocarcinoma, and shown in both epithelial area (normal crypt or malignant area) and stroma area. Mean $\pm S E(n=15-79) . * * p<0.01$ by Student's $t$-test.

Subsequently, we quantitatively evaluated the number of CLIC4 ${ }^{\text {high }}$ cells in malignant epithelial and stromal tissues at three pathological classifications of cancer (i.e., grade, stage, and TNM) in CRC patients. The results demonstrated that the number of CLIC4 ${ }^{\text {high }}$ cells in malignant epithelial tissue of CRC patients at grade 1, stage I, and T2 was significantly higher than that in NAT, and it became significantly lower or tended to be lower according to progression of colorectal lesions. Moreover, the cell number in the stromal tissue at grades 1 and 3, stage IIIb, T4, and N1 was lower than that in the corresponding NATs (Figure 3 ). By contrast, a negligible difference was observed in the number of CLIC4 ${ }^{\text {high }}$ cells among colorectal lesions in the stromal tissue at all the pathological classifications (Figure 4). Suh et al. demonstrated that CLIC4 expression is downregulated in tumor cells and up-regulated in tumor stroma corresponding to the progression of malignancy in CRC patients (7). Thus, our results that showed a tendency of the occurrence of lower numbers of CLIC $4{ }^{\text {high }}$ cells in malignant epithelial tissue, were consistent with the previous results described above (7). However, our data on stromal tissue did not agree with those of Suh et al. This discrepancy between the two studies may be due to a difference in the methods of observation; in our research, CLIC $4{ }^{\text {high }}$ cells were counted, whereas in that of Suh et al. CLIC4 positive areas were observed macroscopically. Comprehensively, our results suggested that CLIC4 expressions in malignant epithelial and stromal tissues of colorectal cancer were a useful predictor for the pathological condition in CRC, as well as that of Suh et al. (7). Another CLIC molecule, CLIC1, is also suggested to be a potential marker in patients with invasive urinary bladder cancer (36). 

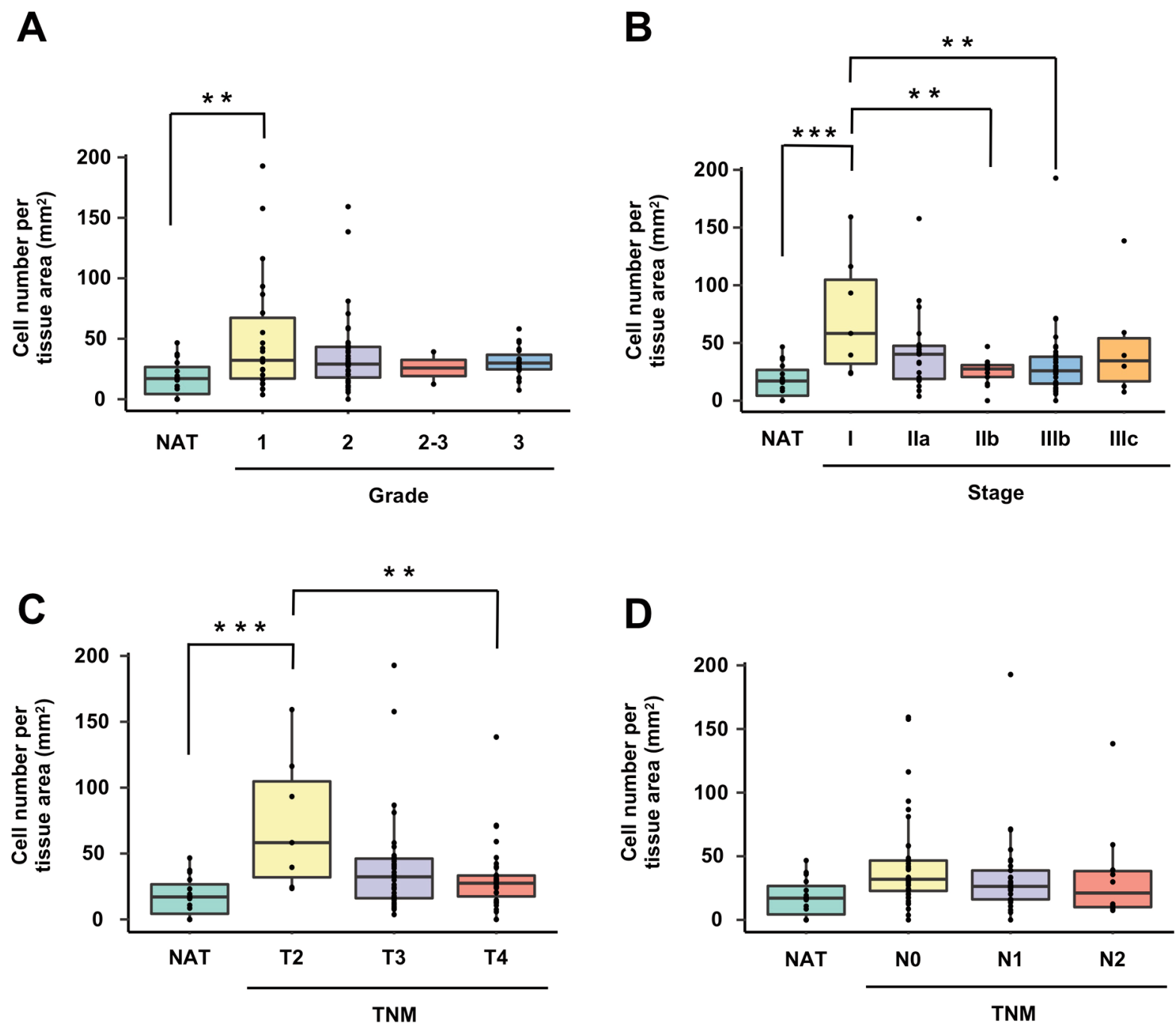

Figure 3. The different number of CLIC4high cells in epithelial area. The number of CLIC4high cells per malignant epithelial tissue area $\left(\mathrm{mm}^{2}\right)$ were estimated by each (A) cancer grade (1, 2, 2-3 and 3), (B) cancer stage (I, IIa, IIb, IIIB and IIIc), (C) tumor stage (T2, T3 and T4) and (D) node stage (NO, N1 and N2) using tumor, node, metastasis (TNM) classification. NAT, cancer adjacent normal colorectal tissue. Mean \pm SE ( $n=2-40)$. **p<0.01 by one-way ANOVA with a post hoc Tukey-kramer test.

Nevertheless, it is not clear as to why the number of CLIC4 $4^{\text {high }}$ cells was higher in early cancerous lesions (grade 1, stage I, and T2) compared to that of NAT and why they were decreased in the later cancerous lesions, and why the cell number in the stromal tissue was lower in various degrees of pathological classifications (grades 1 and 3, stage IIIb, T4, and N1) than that of NAT. One possibility for this phenomenon may be explained by studies on microRNAs. Carofino et al. demonstrated that CLIC4 expression in tumor tissue was attenuated due to the production of microRNA-142-3p from infiltrating immune cells in a squamous cell carcinoma xenograft model mouse (37).
Moreover, Huang et al. suggested that CLIC4 is regulated by microRNAs, transcriptomes, and signal pathways in human acute myeloid leukemia (17). Both malignant epithelial and stromal tissues may be consecutively exposed to CLIC4-targeting microRNAs during the progression of colorectal lesions.

In conclusion, the number of CLIC4 $4^{\text {high }}$ cells in epithelial and peripheral stromal tissues of patients with CRC was significantly suppressed corresponding to an increase in the degree of pathological classification. Further investigation is needed to clarify the molecular mechanisms underlying CLIC4 expression in malignant epithelial and stromal tissues of CRC. 

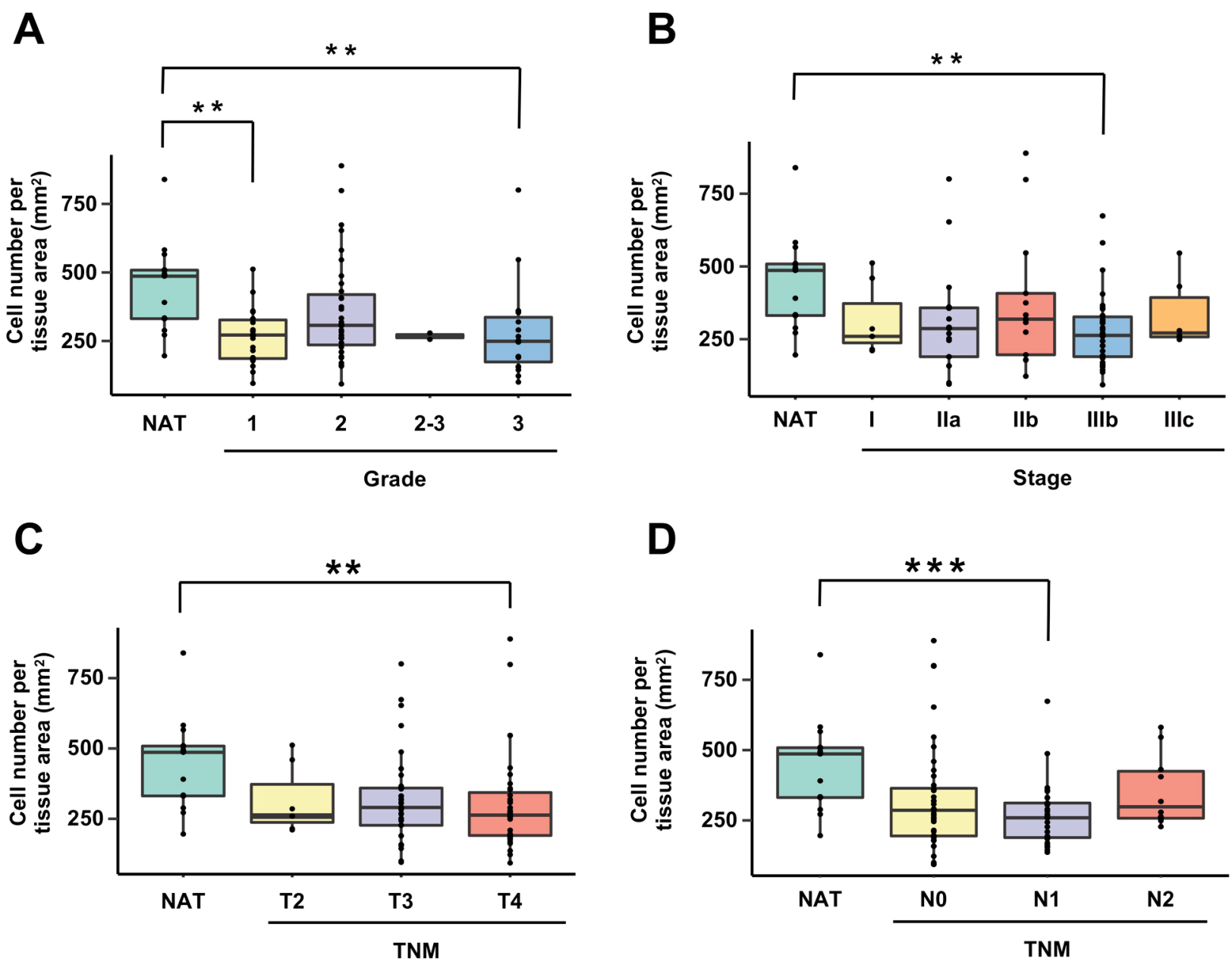

Figure 4. The different number of CLIC4high cells in stromal area. The number of CLIC4high cells per stromal tissue area $\left(\mathrm{mm}^{2}\right)$ were estimated by each (A) cancer grade (1, 2, 2-3 and 3), (B) cancer stage (I, IIa, IIb, IIIB and IIIc), (C) tumor stage (T2, T3 and T4) and (D) node stage (NO, NI and N2) using tumor, node, metastasis (TNM) classification. NAT, cancer adjacent normal colorectal tissue. Mean $\pm S E(n=2-40)$. ** $p<0.01$ by oneway ANOVA with a post hoc Tukey-kramer test.

\section{Conflicts of Interest}

The Authors declare no conflicts of interest.

\section{Authors' Contributions}

Reo Yokoyama and Masaru Terasaki conceived, designed the study and wrote the paper. Reo Yokoyama, Masaru Terasaki and Takuji Tanaka performed the experiments. Atsuhito Kubota, Hiroyuki Kojima, and Michihiro Mutoh reviewed and edited the manuscript. All Authors read and approved the manuscript and agree to be accounted for in all aspects of the research in ensuring that the accuracy or integrity of any part of the work are appropriately investigated and resolved.

\section{Acknowledgements}

This work was supported, in part, by JSPS KAKENHI Grant Number 20K05879.

\section{References}

1 Chou SY, Hsu KS, Otsu W, Hsu YC, Luo YC, Yeh C, Shehab SS, Chen J, Shieh V, He GA, Marean MB, Felsen D, Ding A, Poppas DP, Chuang JZ and Sung CH: CLIC4 regulates apical exocytosis and renal tube luminogenesis through retromer- and actin-mediated endocytic trafficking. Nat Commun 7: 10412, 2016. PMID: 26786190. DOI: 10.1038/ncomms 10412

2 Oakley AJ: Glutathione transferases: new functions. Curr Opin Struct Biol 15(6): 716-723, 2005. PMID: 16263269. DOI: 10.1016/j.sbi.2005.10.005

3 Littler DR, Harrop SJ, Goodchild SC, Phang JM, Mynott AV, Jiang L, Valenzuela SM, Mazzanti M, Brown LJ, Breit SN and Curmi PM: The enigma of the CLIC proteins: Ion channels, redox proteins, enzymes, scaffolding proteins? FEBS Lett 584(10): 20932101, 2010. PMID: 20085760. DOI: 10.1016/j.febslet.2010.01.027

4 Suh KS, Mutoh M, Gerdes M and Yuspa SH: CLIC4, an intracellular chloride channel protein, is a novel molecular target 
for cancer therapy. J Investig Dermatol Symp Proc 10(2): 105-109, 2005. PMID: 16358817. DOI: 10.1111/j.1087-0024.2005.200402.x

5 Tung JJ, Hobert O, Berryman $\mathrm{M}$ and Kitajewski J: Chloride intracellular channel 4 is involved in endothelial proliferation and morphogenesis in vitro. Angiogenesis 12(3): 209-220, 2009. PMID: 19247789. DOI: 10.1007/s10456-009-9139-3

6 Bohman S, Matsumoto T, Suh K, Dimberg A, Jakobsson L, Yuspa S and Claesson-Welsh L: Proteomic analysis of vascular endothelial growth factor-induced endothelial cell differentiation reveals a role for chloride intracellular channel 4 (CLIC4) in tubular morphogenesis. J Biol Chem 280(51): 42397-42404, 2005. PMID: 16239224. DOI: 10.1074/jbc.M506724200

7 Suh KS, Crutchley JM, Koochek A, Ryscavage A, Bhat K, Tanaka T, Oshima A, Fitzgerald P and Yuspa SH: Reciprocal modifications of CLIC4 in tumor epithelium and stroma mark malignant progression of multiple human cancers. Clin Cancer Res 13(1): 121-131, 2007. PMID: 17200346. DOI: 10.1158/ 1078-0432.CCR-06-1562

8 Fernández-Salas E, Sagar M, Cheng C, Yuspa SH and Weinberg WC: p53 and tumor necrosis factor alpha regulate the expression of a mitochondrial chloride channel protein. J Biol Chem 274(51): 36488-36497, 1999. PMID: 10593946. DOI: 10.1074/ jbc. 274.51 .36488

9 Shukla A, Malik M, Cataisson C, Ho Y, Friesen T, Suh KS and Yuspa SH: TGF-beta signalling is regulated by Schnurri-2dependent nuclear translocation of CLIC4 and consequent stabilization of phospho-Smad2 and 3. Nat Cell Biol 11(6): 777784, 2009. PMID: 19448624. DOI: $10.1038 / \mathrm{ncb} 1885$

10 Shiio Y, Suh KS, Lee H, Yuspa SH, Eisenman RN and Aebersold R: Quantitative proteomic analysis of myc-induced apoptosis: a direct role for Myc induction of the mitochondrial chloride ion channel, mtCLIC/CLIC4. J Biol Chem 281(5): 2750-2756, 2006. PMID: 16316993. DOI: 10.1074/jbc.M509349200

11 Okudela K, Katayama A, Woo T, Mitsui H, Suzuki T, Tateishi Y, Umeda S, Tajiri M, Masuda M, Nagahara N, Kitamura H and Ohashi K: Proteome analysis for downstream targets of oncogenic KRAS - the potential participation of CLIC4 in carcinogenesis in the lung. PLoS One 9(2): e87193, 2014. PMID: 24503901. DOI: 10.1371/journal.pone.0087193

12 Shukla A, Edwards R, Yang Y, Hahn A, Folkers K, Ding J, Padmakumar VC, Cataisson C, Suh KS and Yuspa SH: CLIC4 regulates TGF- $\beta$-dependent myofibroblast differentiation to produce a cancer stroma. Oncogene 33(7): 842-850, 2014. PMID: 23416981. DOI: 10.1038/onc.2013.18

13 Rønnov-Jessen L, Villadsen R, Edwards JC and Petersen OW: Differential expression of a chloride intracellular channel gene, CLIC4, in transforming growth factor-beta1-mediated conversion of fibroblasts to myofibroblasts. Am J Pathol 161(2): 471-480, 2002. PMID: 12163372. DOI: 10.1016/s0002-9440 (10)64203-4

14 Xue H, Lu J, Yuan R, Liu J, Liu Y, Wu K, Wu J, Du J and Shen B: Knockdown of CLIC4 enhances ATP-induced HN4 cell apoptosis through mitochondrial and endoplasmic reticulum pathways. Cell Biosci 6: 5, 2016. PMID: 26816615. DOI: 10.1186/s13578-016-0070-1

15 Zou Q, Yang Z, Li D, Liu Z and Yuan Y: Association of chloride intracellular channel 4 and Indian hedgehog proteins with survival of patients with pancreatic ductal adenocarcinoma. Int J Exp Pathol 97(6): 422-429, 2016. PMID: 28205343. DOI: 10.1111/iep.12213
16 Kenny TC, Schmidt H, Adelson K, Hoshida Y, Koh AP, Shah N, Mandeli J, Ting J and Germain D: Patient-derived interstitial fluids and predisposition to aggressive sporadic breast cancer through collagen remodeling and inactivation of p53. Clin Cancer Res 23(18): 5446-5459, 2017. PMID: 28630214. DOI: 10.1158/1078-0432.CCR-17-0342

17 Huang S, Huang Z, Chen P and Feng C: Aberrant chloride intracellular channel 4 expression is associated with adverse outcome in cytogenetically normal acute myeloid leukemia. Front Oncol 10: 1648, 2020. PMID: 33014825. DOI: 10.3389 /fonc. 2020.01648

18 Zhu L, Chen Q, Zhang L, Hu S, Zheng W, Wang C, Bai Y, Pan Y, Konishi T, Guan J and Shao C: CLIC4 regulates radioresistance of nasopharyngeal carcinoma by iNOS after $\gamma$-rays but not carbon ions irradiation. Am J Cancer Res 10(5): 1400-1415, 2020. PMID: 32509387.

19 Ferlay J, Colombet M, Soerjomataram I, Mathers C, Parkin DM, Piñeros M, Znaor A and Bray F: Estimating the global cancer incidence and mortality in 2018: GLOBOCAN sources and methods. Int J Cancer 144(8): 1941-1953, 2019. PMID: 30350310. DOI: $10.1002 / \mathrm{ijc} .31937$

20 Cancer Genome Atlas Network: Comprehensive molecular characterization of human colon and rectal cancer. Nature 487(7407): 330-337, 2012. PMID: 22810696. DOI: 10.1038/ nature 11252

21 Pearlman R, Frankel WL, Swanson B, Zhao W, Yilmaz A, Miller K, Bacher J, Bigley C, Nelsen L, Goodfellow PJ, Goldberg RM, Paskett E, Shields PG, Freudenheim JL, Stanich PP, Lattimer I, Arnold M, Liyanarachchi S, Kalady M, Heald B, Greenwood C, Paquette I, Prues M, Draper DJ, Lindeman C, Kuebler JP, Reynolds K, Brell JM, Shaper AA, Mahesh S, Buie N, Weeman K, Shine K, Haut M, Edwards J, Bastola S, Wickham K, Khanduja KS, Zacks R, Pritchard CC, Shirts BH, Jacobson A, Allen B, de la Chapelle A, Hampel H and Ohio Colorectal Cancer Prevention Initiative Study Group: Prevalence and spectrum of germline cancer susceptibility gene mutations among patients with early-onset colorectal cancer. JAMA Oncol 3(4): 464-471, 2017. PMID: 27978560. DOI: 10.1001/jamaoncol.2016.5194

22 Fearon ER: Molecular genetics of colorectal cancer. Annu Rev Pathol 6: 479-507, 2011. PMID: 21090969. DOI: 10.1146/ annurev-pathol-011110-130235

23 Yuan W, Li X, Liu L, Wei C, Sun D, Peng S and Jiang L: Comprehensive analysis of IncRNA-associated ceRNA network in colorectal cancer. Biochem Biophys Res Commun 508(2): 374379, 2019. PMID: 30503344. DOI: 10.1016/j.bbrc.2018.11.151

24 Wu Y, Wang X, Wu F, Huang R, Xue F, Liang G, Tao M, Cai P and Huang Y: Transcriptome profiling of the cancer, adjacent non-tumor and distant normal tissues from a colorectal cancer patient by deep sequencing. PLoS One 7(8): e41001, 2012. PMID: 22905095. DOI: 10.1371/journal.pone.0041001

25 Fehlker M, Huska MR, Jöns T, Andrade-Navarro MA and Kemmner W: Concerted down-regulation of immune-system related genes predicts metastasis in colorectal carcinoma. BMC Cancer 14: 64, 2014. PMID: 24495478. DOI: 10.1186/1471-2407-14-64

26 Medema JP and Vermeulen L: Microenvironmental regulation of stem cells in intestinal homeostasis and cancer. Nature 474(7351): 318-326, 2011. PMID: 216777488. DOI: 10.1038/ nature 10212

27 Mariani F, Sena P and Roncucci L: Inflammatory pathways in the early steps of colorectal cancer development. World J 
Gastroenterol 20(29): 9716-9731, 2014. PMID: 25110410. DOI: 10.3748/wjg.v20.i29.9716

28 Legitimo A, Consolini R, Failli A, Orsini G and Spisni R: Dendritic cell defects in the colorectal cancer. Hum Vaccin Immunother 10(11): 3224-3235, 2014. PMID: 25483675. DOI: 10.4161/hv.29857

29 Deng YJ, Tang N, Liu C, Zhang JY, An SL, Peng YL, Ma LL, Li GQ, Jiang Q, Hu CT, Wang YN, Liang YZ, Bian XW, Fang WG and Ding YQ: CLIC4, ERp29, and Smac/DIABLO derived from metastatic cancer stem-like cells stratify prognostic risks of colorectal cancer. Clin Cancer Res 20(14): 3809-3817, 2014. PMID: 24916695. DOI: 10.1158/1078-0432.CCR-13-1887

30 Chen WJ, Ho CC, Chang YL, Chen HY, Lin CA, Ling TY, Yu SL, Yuan SS, Chen YJ, Lin CY, Pan SH, Chou HY, Chen YJ, Chang GC, Chu WC, Lee YM, Lee JY, Lee PJ, Li KC, Chen HW and Yang PC: Cancer-associated fibroblasts regulate the plasticity of lung cancer stemness via paracrine signalling. Nat Commun 5: 3472, 2014. PMID: 24668028. DOI: $10.1038 /$ ncomms 4472

31 Kalluri R and Zeisberg M: Fibroblasts in cancer. Nat Rev Cancer 6(5): 392-401, 2006. PMID: 16572188. DOI: $10.1038 / \mathrm{nrc} 1877$

32 Valencia T, Kim JY, Abu-Baker S, Moscat-Pardos J, Ahn CS, Reina-Campos M, Duran A, Castilla EA, Metallo CM, DiazMeco MT and Moscat J: Metabolic reprogramming of stromal fibroblasts through p62-mTORC1 signaling promotes inflammation and tumorigenesis. Cancer Cell 26(1): 121-135, 2014. PMID: 25002027. DOI: 10.1016/j.ccr.2014.05.004

33 Adegboyega PA, Mifflin RC, DiMari JF, Saada JI and Powell DW: Immunohistochemical study of myofibroblasts in normal colonic mucosa, hyperplastic polyps, and adenomatous colorectal polyps. Arch Pathol Lab Med 126(7): 829-836, 2002. PMID: 12088453. DOI: 10.5858/2002-126-0829-ISOMIN
34 Ikuta D, Miyake T, Shimizu T, Sonoda H, Mukaisho KI, Tokuda A, Ueki T, Sugihara H and Tani M: Fibrosis in metastatic lymph nodes is clinically correlated to poor prognosis in colorectal cancer. Oncotarget 9(51): 29574-29586, 2018. PMID: 30038705. DOI: $10.18632 /$ oncotarget.25636

35 Sahai E, Astsaturov I, Cukierman E, DeNardo DG, Egeblad M, Evans RM, Fearon D, Greten FR, Hingorani SR, Hunter T, Hynes RO, Jain RK, Janowitz T, Jorgensen C, Kimmelman AC, Kolonin MG, Maki RG, Powers RS, Puré E, Ramirez DC, Scherz-Shouval R, Sherman MH, Stewart S, Tlsty TD, Tuveson DA, Watt FM, Weaver V, Weeraratna AT and Werb Z: A framework for advancing our understanding of cancer-associated fibroblasts. Nat Rev Cancer 20(3): 174-186, 2020. PMID: 31980749. DOI: $10.1038 / \mathrm{s} 41568-019-0238-1$

36 Adelmann TG, Camerota TC, Ceausu AR, Cimpean AM, Mazzanti M and Raica M: Chloride intracellular channel protein 1 (CLIC1) is over-expressed in muscle invasive urinary bladder cancer. Anticancer Res 40(12): 6879-6884, 2020. PMID: 33288580. DOI: 10.21873 /anticanres.14710

37 Carofino BL, Dinshaw KM, Ho PY, Cataisson C, Michalowski AM, Ryscavage A, Alkhas A, Wong NW, Koparde V and Yuspa SH: Head and neck squamous cancer progression is marked by CLIC4 attenuation in tumor epithelium and reciprocal stromal upregulation of miR-142-3p, a novel post-transcriptional regulator of CLIC4. Oncotarget 10(68): 7251-7275, 2019. PMID: 31921386. DOI: 10.18632/oncotarget.27387

Received August 10, 2021

Revised September 10, 2021 Accepted September 30, 2021 